\title{
PROACTIVE INDUSTRIAL DEVELOPMENT STRATEGIES AND PORTFOLIO ANALYSIS
}

\author{
Niles C. Schoening and Larry E. Sweeney*
}

\section{INTRODUCTION}

In recent years, some communities have adopted an industrial development strategy where firms and industries are actively recruited before they have shown an interest in relocating. This "proactive" strategy is usually initiated with the preparation of a targeted industries list. This targeted industries list is then used to prioritize the initial contacts with potentially relocating firms. It is generally based on the locational advantages offered by the community-transportation services, labor skills, prevailing wages, and local taxes-as well as on the targeted industry's compatibility with the community's existing industrial base.

The analytical concepts of security portfolio theory can be applied to measure a targeted industry's compatibility with the community's existing industrial base. The model introduced in Part II of this paper allows for the measurement of the trade-off between employment growth and employment instability. The basic premises underlying this application are that employment and income instability in a region is analogous to risk in securities markets and that economic growth is similar to the return on a security portfolio. It is also assumed that the community leadership values economic growth and wishes to minimize future employment and income fluctuations.

The use of portfolio analysis to find the optimal industrial mix is limited by both empirical and theoretical considerations. The succeeding sections of this paper explore the extent and severity of the limitations, especially when portfolio analysis is applied to the preparation of a targeted industries list for a small region.

\section{THEORETICAL LIMITATIONS}

Portfolio analysis was initially developed to help investors choose a diversified grouping of securities that minimized risk and maximized returns. The returns of individual securities can be expected to vary over time due to ex-

\footnotetext{
*Associate Professor of Economics, University of Alabama in Huntsville, and Assistant Professor of Finance, Ball State University, respectively.
} 
ogenous and endogenous impacts on the performance of the firm and on securities markets. Since returns are stochastic, an investor should not only consider the expected returns, but also the variance of those returns over time. An investor can expect to reduce the variance of expected returns by investing in a diversified portfolio.

Following Markowitz's (1952) formulation of risk and return measurement for securities portfolios, the return for portfolio $R_{p}$ is defined as:

$$
R_{p}=\sum_{1}^{i} w_{i} R_{i}
$$

The portfolio variance, $\operatorname{Var}(p)$, is defined as:

$$
\operatorname{Var}(p)=\sum_{i} \sum_{j} w_{i} w_{j} \sigma_{i j}
$$

where $w_{i}$ and $w_{j}$ are the proportions of securities $i$ and $j$ in the portfolio. Equation (2) can be rearranged to reveal the variance and covariance components:

$$
\operatorname{Var}(p)=\sum_{i} w_{i}^{2} \sigma_{i}^{2}+\sum_{i \neq j} \sum_{j \neq i} w_{i} w_{j} \sigma_{i j}
$$

Equation (3) illustrates that negative covariances can reduce overall portfolio variance. Even if there are no negative correlations among individual securities, benefits of diversification still can be realized as long as the correlations are not perfect $(+1)$. Since there are few security returns that are perfectly correlated, an investor is assured that a portfolio will give better results than an individual security. If an investor makes random selections of securities for the portfolio, he or she can improve risk and return performance up to an asymptotic limit. For example, in a portfolio of $N$ securities, each having equal weight, the total portfolio variance is:

$$
\operatorname{Var}(p)=[N \cdot \operatorname{VAR}+N(N-1) C O V] / N^{2}
$$

where $V A R$ is the average variance of the securities and $C O V$ the average covariance. Combining and rearranging the terms result in the expression:

$$
\begin{aligned}
& \operatorname{Var}(p)=\frac{V A R}{N}+\left(1-\frac{1}{N}\right) \operatorname{COV} \\
& \text { As } N \rightarrow \infty \\
& \operatorname{Var}(p)=\operatorname{COV}
\end{aligned}
$$

Hence, for a portfolio with a large number of securities, the average covariance provides an approximation of portfolio variance.

From this analysis, it is apparent that there are three limitations to the use of portfolio theory to find a set of targeted industries. First, industries are not as divisible as securities. Consequently, in a regional application, the weights $w_{i}$ and 
$w_{j}$ in Equation (2) that minimize total portfolio variance may not be attainable because individual industrial plants do not conform to the optimal sizes found by analysis. Second, $N$ will usually be small for a portfolio of industries, and the weights of the industries will be unequal, which means that the variance terms in Equation (3) will remain important, thereby limiting the potential benefits of recruiting industries to minimize overall portfolio variance. These benefits probably vary by the size of the region since $N$ is likely to be greater the larger the region.

The third limitation occurs when one attempts to rank alternative portfolios. For example, is a portfolio having a return of 15 percent and a variance of 5 percent superior to one with a return of 12 percent and a variance of 4.2 percent? For a financial portfolio, finding the optimal choice must be predicated on a precise knowledge of the risk-return trade-off function of the individual investor. It is problematical that this function can be found for a region.

Some investigators in the field of finance have tried to avoid this last problem by using statistical measures such as the coefficient of variation (Weston and Brigham 1972), which is defined as the standard deviation of a portfolio divided by its expected return. The statistical distribution of the coefficient of variation is unknown, however, so there is no way to determine when differences in this measure are significant. Other performance indices for securities portfolios, such as those suggested by Sharpe (1966), Jensen (1968), and Treynor (1965), depend on market measures and riskless securities, which prevents them from being applied to regional portfolios of industries.

As a consequence of these inadequacies, the mean-variance approach to portfolio analysis does not always allow the analyst to rank portfolios of financial assets unless they have either a common return or a variance. This dilemma and others associated with portfolio theory led to the development of the Capital Asset Pricing Model (CAPM) by Sharpe (1964), Lintner (1965), Mossin (1966), and others. The CAPM eliminates the need for knowledge of the investor's riskreturn trade-off function, but its adaptation to the problem of ranking regional industrial portfolios does not appear to be possible. There is no recognizable "market" for trading industries, nor is there a "risk-free" industry. These are both required in the CAPM.

The work of Markowitz (1956) and Wolfe (1959) has shown that a quadratic programming variant of the basic linear programming algorithm can be used to find optimal portfolios, given some preselected securities and levels of return. The problem of negative weights for industries that cannot be sold short is avoided by using non-negative constraints as shown in Francis and Archer (1971). This extension of portfolio analysis avoids the theoretical difficulty of ranking alternative portfolios. If levels of return are fixed, the impact of securities added to an exist- 
ing portfolio can be ascertained. This procedure is directly applicable to the targeted industry problem if the lumpiness of the industrial portfolio is also accounted for in the constraints of the program.

Further limitations arise because of the inadequacy of local employment data, especially in small regions. These limitations are discussed in the next section of the paper.

\section{EMPIRICAL LIMITATIONS}

Conroy's (1974) introduction of portfolio theory changed the way in which industrial diversification was viewed in the regional economics literature. Earlier, Richardson (1969) pointed out that limiting the recruitment of firms to those in noncyclical industries was likely to be unsuccessful because all regions could not possess the few stable industries to the exclusion of the unstable ones. Conroy recognized that favoring an industry with a low employment variance over one with a high variance may increase instability because the low variance choice may not match up with the variances of existing industries; consequently, this strategy could have the perverse effect of increasing overall employment instability.

Conroy was the first to apply portfolio theory to the problem of industrial diversification (1975). He created a new measure of diversity that explained more of the cyclical employment variation in 52 U.S. metropolitan areas than did other well-known measures (these other measures are discussed in Conroy [1975], Bahl [1971], Wasylenko and Erickson [1978], and Grossberg [1982]). Conroy also showed how a short-term industrial development strategy could be derived from the analysis and applied to the problem of regional employment instability.

Conroy's studies made an important contribution to the understanding of regional employment instability; however, a number of important empirical limitations were overlooked in his papers. First, he did not measure employment growth and relate it to instability. Clearly, the trade-offs between growth (or return) and instability (or risk) are different in each of the metropolitan areas he sampled. Each probably has a unique risk-return trade-off function that he did not measure; consequently, little can be concluded about each area's ranking. Adding industries that lower a particular metropolitan area's total portfolio variance may not improve a region's industrial mix because the new industries could have a large, negative effect on total return.

Conroy used monthly three-digit SIC data for the U.S. manufacturing sector to devise the variance-covariance matrices for each metropolitan area. These variance-covariance matrices probably do not reflect the actual variation in employment in a particular metropolitan area. Schoening and Sweeney (1989) 
showed that for several small regions, there was a statistically significant difference between total portfolio variance when it was measured using national or local three-digit employment data. This aggregation problem probably holds for many of the metropolitan areas in Conroy's sample as well.

Conroy calculated the covariance terms against a quadratic time trend that was standardized with respect to the mean of each time series. Each element in the matrix was determined using the following relationship:

$$
\hat{\sigma}_{i j}=\left(\frac{1}{N-2}\right)\left(m_{i t}-\frac{T R E N D_{i t}}{A V G_{i}}\right)\left(m_{j t}-\frac{T R E N D_{j t}}{A V G_{j}}\right)
$$

where $m_{i t}$ and $m_{j t}$ denote observed levels of manufacturing employment in industries $i$ and $j$ during month $t, T R E N D_{i t}$ and TREND $D_{j t}$ are predicted levels of employment given by the quadratic trend equation, and $A V G_{i}$ and $A V G_{j}$ are the arithmetic means of the time series for industries $i$ and $j$. This method of determining covariances also was used by Jackson (1984) and Spahr and Deckro (1988).

Measuring the variance of an industry from its trend line rather than from its mean may over- or underestimate total portfolio variance and is not analogous to the measure used in security portfolios. It introduces biases into the measurement of overall risk and could lead to a misstatement of the risk-return trade-off faced by a particular region. This problem was confronted by Cho and Scheurmann (1980) and St. Louis (1980). Their models based the variance-covariance matrix on the monthly percent change in industry employment where each element consisted of a covariance of the following form:

$$
\hat{\sigma}_{i j}=\left[\frac{1}{N-2}\right]\left[g_{i t}-\hat{y}_{i}\right]\left[g_{j t}-\hat{y}_{j}\right]
$$

where: $g_{i t}=\frac{m_{i t+1}-m_{i t}}{m_{i t}}$

and: $\quad \hat{y}_{i t}=\frac{1}{N} \sum_{i}^{N} g_{i t}$

This method may work in larger regions with several plants in each threedigit category, but it is unlikely to give satisfactory results in small- or mediumsized regions where there are only one or two plants in a particular industry. In these cases, there may be zero entries in the time series caused by periodic plant shutdowns and reopenings. The month-to-month percent change $g_{i t}$ would then fall to zero during the shutdown period, and therefore, the measured variance 
would be smaller than if the absolute change from the time series mean were used instead.

This method also leads to problems of interpretation. Should one be minimizing employment instability from month to month or from year to year? Using unadjusted monthly data is problematic because it includes normal seasonal swings as well as the more important cyclical effects. In devising a long-term strategy to reduce employment instability, it is probably more appropriate to ignore seasonal shifts and concentrate on shifts caused by the business cycle.

The appropriate measure of return is an empirical question that has been partly examined in one study. Most research has been based on minimizing employment fluctuations; however, Kurre and Woodruff (1990) found that employment data seriously understated instability as compared to income data for the region they studied. Whether to optimize a portfolio of industries to stabilize income or employment is a matter of regional preference. Like the risk-return trade-off function, this too is unknown to the researcher without prior knowledge of the region's long-term economic development goals.

If regional preferences can be determined, it appears that portfolio analysis can be used to assist in identifying the industries that should be placed on a targeted industries list. This simulation is possible only if the variances and covariances for a potential new industry can be approximated using data from another region. When the other region has different factor endowments or is quite large, these data probably will not accurately reflect the performance of the industries in the new region. A better alternative may be to use data from similarly sized regions in the "neighborhood" of the region under study.

This "neighborhood" approach is tested in the following section. Also tested is the sensitivity of a small region's industrial portfolio to changes in risks and returns as measured by employment. A simulation of the entry of a new industry also is tested for sensitivity to shifts in risk and return.

\section{AN APPLICATION OF PORTFOLIO ANALYSIS IN TWO SMALL REGIONS}

The industrial portfolios of two rural northern Alabama counties were analyzed using the method developed by Francis and Archer (1971). The portfolio weights corresponding to $w_{i}$ and $w_{j}$ in Equations (2) and (3) are the proportion of employment in industry $i$ and $j$ to total manufacturing employment in the county in 1985. The actual weights appear in column 2 of Table 1, and the corresponding three-digit manufacturing industries in the county are displayed in column 1. 
TABLE 1

Optimizing Existing Portfolios

\begin{tabular}{|c|c|c|c|c|c|}
\hline \multicolumn{6}{|c|}{ Case 1: Cullman County } \\
\hline \multirow[b]{2}{*}{$\begin{array}{l}\text { Industry } \\
\text { SIC Code }\end{array}$} & \multirow{2}{*}{$\begin{array}{l}\text { Actual } \\
\text { Portfolio } \\
\text { Weights }\end{array}$} & \multicolumn{4}{|c|}{ Return (Compounded Annual Increase in Employment) } \\
\hline & & $2.5 \%$ & $3 \%$ & $6 \%$ & $7 \%$ \\
\hline 201 & 0.172 & 0.352 & 0.390 & 0.323 & 0.241 \\
\hline 207 & 0.005 & 0.019 & 0.019 & 0.018 & 0.013 \\
\hline 232 & 0.152 & 0.038 & 0.038 & 0.037 & 0.030 \\
\hline 234 & 0.047 & 0.245 & 0.245 & 0.231 & 0.196 \\
\hline 236 & 0.028 & 0.000 & 0.000 & 0.000 & 0.000 \\
\hline 242 & 0.015 & 0.037 & 0.037 & 0.034 & 0.027 \\
\hline 265 & 0.022 & 0.001 & 0.000 & 0.000 & 0.000 \\
\hline 271 & 0.011 & 0.013 & 0.013 & 0.001 & 0.000 \\
\hline 342 & 0.216 & 0.003 & 0.003 & 0.001 & 0.000 \\
\hline 346 & 0.127 & 0.123 & 0.126 & 0.179 & 0.323 \\
\hline 349 & 0.058 & 0.005 & 0.004 & 0.003 & 0.000 \\
\hline 358 & 0.147 & 0.164 & 0.164 & 0.165 & 0.167 \\
\hline \multicolumn{6}{|c|}{$\begin{array}{l}\text { Portfolio Variance } \\
\operatorname{Var}(\mathrm{p})\end{array}$} \\
\hline \multicolumn{6}{|c|}{ Case 2: Franklin County } \\
\hline 204 & 0.078 & 0.000 & 0.000 & 0.000 & 0.000 \\
\hline 232 & 0.342 & 0.227 & 0.129 & 0.093 & 0.056 \\
\hline 242 & 0.027 & 0.191 & 0.185 & 0.182 & 0.180 \\
\hline 245 & 0.205 & 0.263 & 0.316 & 0.335 & 0.355 \\
\hline 251 & 0.119 & 0.019 & 0.032 & 0.037 & 0.042 \\
\hline 329 & 0.059 & 0.086 & 0.102 & 0.108 & 0.114 \\
\hline 334 & 0.031 & 0.171 & 0.195 & 0.204 & 0.213 \\
\hline 379 & 0.111 & 0.011 & 0.023 & 0.026 & 0.030 \\
\hline 396 & 0.027 & 0.031 & 0.019 & 0.014 & 0.009 \\
\hline $\begin{array}{l}\text { Portfolio Variance } \\
\operatorname{Var}(\mathrm{p})\end{array}$ & 9.5400 & 2.5910 & 3.5141 & 3.9395 & 4.4082 \\
\hline
\end{tabular}

A program was written using LINDO (Schrage 1986) to minimize the existing portfolio variance, $\operatorname{Var}(\mathrm{p})$, as rates of return increased from 2.5 percent to 7 percent (the rate of return is measured by the compounded annual growth rate of manufacturing employment). The new industry weights and total portfolio variances appear in columns 3 through 6 of Table 1 beneath the rate of return for which the analysis was performed.

The portfolio weights that minimize $\operatorname{Var}(\mathrm{p})$ at each rate of return are drastically different from the actual weights; however, after the initial reweighting, they do not change very much as the rate of return is increased. Similarly, the trade-off 
between $\operatorname{Var}(p)$ and rate of return is slight in both counties. In Case 1, Var (p) grows from 1.3345 to 1.7892 as the rate of return increases to 7 percent. In Case 2 , the increase in $\operatorname{Var}(p)$ is from 2.5910 to 4.4082 .

The large shifts in the weights appear to preclude the development of a stabilization policy based on the existing mix of industries. Such a policy would require shutting down firms and encouraging the drastic contraction of others. A more likely policy option is to attract new industries that complement the existing portfolio of firms by reducing overall employment fluctuations.

The researcher is now faced with the task of choosing which industries to test for their effect on portfolio variance. Industries can be picked by using national or state employment data or local data from nearby counties. Using national or state data gives a wider array of choices, but the variances probably will not reflect the impact of local factor endowments. Choosing industries that are present in neighboring counties but absent from the county under investigation might offer a solution to this problem.

This "neighborhood" approach was tested by using a small sample likelihood ratio test. Seven three-digit industries included in the test were present in Cullman County and in two adjacent counties-Marshall and Morgan. The same test also was performed on five other three-digit industries located in Franklin, Marshall, and Morgan counties. State and U.S. data for these two groups of industries also were used. All data were drawn from County Business Patterns for the period 1966-1985 and were standardized with respect to the mean to eliminate scaling problems. The chi square values for the small sample likelihood ratio tests are displayed in Table 2.

As expected, all of the industry variances calculated from U.S. numbers were significantly different from those calculated using local numbers. Eleven out of twelve variances calculated from state numbers also were significantly different.

The results were much better when variances in the two counties being studied were compared to the variances of industries located in neighboring counties. The variances of only three of the twelve industries located in Marshall County were significantly different from their counterparts in Franklin and Cullman counties. Five of ten were different for industries in Morgan County. These data appear to support the idea that the "neighborhood" approach provides more reliable results, since nearby locations are more likely to have similar factor endowments. For this reason, one might have a higher expectation that the employment history of the industry in the new location would be similar to the one in the nearby location. In any case, these results confirm earlier findings that variances calculated from geographically aggregated data are nearly always different from variances based on local data. 
TABLE 2

Likelihood Ratio Tests of Differences among

Measures of Employment Variances

\begin{tabular}{|c|c|c|c|c|}
\hline $\begin{array}{l}\text { Industry } \\
\text { SIC Code }\end{array}$ & $\begin{array}{c}\text { U.S. } \\
\text { Minus } \\
\text { Cullman County }\end{array}$ & $\begin{array}{c}\text { Alabama } \\
\text { Minus } \\
\text { Cullman County }\end{array}$ & $\begin{array}{l}\text { Marshall County } \\
\text { Minus } \\
\text { Cullman County }\end{array}$ & $\begin{array}{c}\text { Morgan County } \\
\text { Minus } \\
\text { Cullman County }\end{array}$ \\
\hline 201 & $64.599^{2}$ & $3.601^{c}$ & 1.012 & $5.076^{6}$ \\
\hline 207 & $79.919^{a}$ & $61.502^{2}$ & 1.082 & 0.980 \\
\hline 232 & $55.056^{\mathrm{a}}$ & $32.774^{a}$ & $15.653^{\mathrm{a}}$ & $11.553^{\mathrm{a}}$ \\
\hline 251 & $81.002^{a}$ & $40.139^{a}$ & 2.673 & 0.976 \\
\hline 271 & $67.661^{a}$ & $52.381^{\mathrm{a}}$ & 2.376 & $3.674^{c}$ \\
\hline 342 & $65.414^{\mathrm{a}}$ & $3.468^{c}$ & $3.897^{b}$ & $8.404^{a}$ \\
\hline 359 & $11.448^{\mathrm{a}}$ & 1.3989 & 1.582 & 1.020 \\
\hline \multicolumn{5}{|c|}{$\begin{aligned} a & =\text { Significant at the } .01 \text { level } \\
b & =\text { Significant at the } .05 \text { level } \\
c & =\text { Significant at the } .10 \text { level }\end{aligned}$} \\
\hline $\begin{array}{l}\text { Industry } \\
\text { SIC Code }\end{array}$ & $\begin{array}{c}\text { U.S. } \\
\text { Minus } \\
\text { Franklin County }\end{array}$ & $\begin{array}{c}\text { Alabama } \\
\text { Minus } \\
\text { Franklin County }\end{array}$ & $\begin{array}{c}\text { Marshall County } \\
\text { Minus } \\
\text { Franklin County }\end{array}$ & $\begin{array}{l}\text { Morgan County } \\
\text { Minus } \\
\text { Franklin County }\end{array}$ \\
\hline 204 & $91.937^{2}$ & $38.031^{2}$ & $19.1764^{\mathrm{a}}$ & 2.0382 \\
\hline 232 & $19.884^{2}$ & $4.9654^{b}$ & 1.0821 & 1.9726 \\
\hline 245 & $54.301^{\mathrm{a}}$ & $56.046^{\mathrm{a}}$ & 1.0827 & NA \\
\hline 251 & $65.492^{\mathrm{a}}$ & $35.575^{a}$ & 1.6568 & $49.666^{a}$ \\
\hline 329 & $62.425^{\mathrm{a}}$ & $34.257^{\mathrm{a}}$ & 1.2946 & NA \\
\hline
\end{tabular}

$\mathrm{a}=$ Significant at the .01 level.

$\mathrm{b}=$ Significant at the .05 level.

c = Significant at the .10 level.

NA $=$ Not available.

A question remains regarding whether the use of aggregated data has any practical effect on selecting the new industry, which minimizes the local Var (p). Such a test was performed on the two counties using data from the United States, the state, and nearby counties for seven three-digit industries. The same program that was used earlier was employed again. It was assumed that the new industry or industries would make up 10 percent of total manufacturing employment in each county. Total portfolio variance declined in each case, but different industries were chosen and different weights were assigned, depending on the source of the data and the rate of return.

The results of the simulations appear in Table 3. Using nearby county data resulted in choosing SIC 249 in Cullman County (weight $=.093$ ) when the rate of return was set at 3 percent. State data shifted the choice to SIC 243 (weight $=$ .094), while national data selected three industries: SIC 243, 249, and 285. In 
TABLE 3

Testing the Impact of a New Industry

\begin{tabular}{|c|c|c|c|c|c|c|c|c|}
\hline \multicolumn{9}{|c|}{ Case 1: Cullman County } \\
\hline & \multicolumn{6}{|c|}{ Industry SIC Code } & \multirow[b]{2}{*}{369} & \multirow[b]{2}{*}{$\operatorname{Var}(p)$} \\
\hline & 229 & 243 & 249 & 285 & 335 & 363 & & \\
\hline \multicolumn{9}{|l|}{3 percent return: } \\
\hline Nearby county data & & & 0.093 & & & & .007 & 2.1962 \\
\hline State data & & 0.094 & 0.006 & & & & & 2.5220 \\
\hline U.S. data & & 0.013 & 0.056 & 0.031 & & & & 2.1805 \\
\hline \multicolumn{9}{|l|}{10 percent return: } \\
\hline Nearby county data & & & & & & & 0.10 & 2.4665 \\
\hline State data & & 0.055 & & & 0.045 & & & 3.1730 \\
\hline U.S. data & & 0.056 & 0.044 & & & & & 2.5989 \\
\hline \multicolumn{9}{|c|}{ Case 2: Franklin County } \\
\hline \multicolumn{9}{|l|}{3 percent return } \\
\hline Nearby county data & & & & & 0.10 & & & 3.2450 \\
\hline State data & & & & & 0.10 & & & 3.1600 \\
\hline U.S. data & 0.025 & & 0.025 & 0.025 & 0.025 & & & 3.1563 \\
\hline \multicolumn{9}{|l|}{10 percent return: } \\
\hline Nearby county data & & & 0.036 & & & & 0.064 & 3.2760 \\
\hline State data & & & 0.055 & & & 0.045 & & 4.0234 \\
\hline U.S. data & & 0.10 & & & & & & 3.2230 \\
\hline
\end{tabular}

Franklin County, the same industry was chosen when either state or nearby county data were used, but the results were quite different when using U.S. data.

When the rate of return was increased to 10 percent, the industry choices changed in both counties and were also different depending on the data source. To conclude, it appears that the data source did make a difference when portfolio analysis was applied to the problem of choosing a new industry. The desired rate of return also affected the outcome of the simulation.

\section{CONCLUSION}

The application of portfolio analysis to industrial recruitment strategies is limited by both theoretical and empirical considerations. This seems to be especially true when it is applied to regions with small numbers of industries.

Using portfolio analysis to identify optimal industry weights can indicate ways to reduce employment fluctuations in an existing mix of industries; but, be- 
cause a portfolio of industries can be changed only very slowly, this result is of little practical assistance in setting a community's industrial recruitment strategy.

Simulating the impact of the entry of a new industry appears to be a more promising application; however, there are two factors that impact even this limited approach. First, the risk-return preference for the region must be known in order to pick the optimal portfolio of industries. Second, the simulations require data for entering industries that accurately reflect the likely future performance of the industry in its new location.

Aggregation error seems serious in this case. Because of data disclosure problems at the local level, researchers have been forced to use proxy data from larger regions. Data from larger regions gave different results than data from neighboring regions in the two simulations the researchers performed for this paper. The "neighborhood" approach introduced in the paper seems to provide a solution to the aggregation problem, but its application in most regions likely will lead to a short list of industries that can be tested for compatibility with a region's existing industrial base. This approach leaves a large subset of potential solutions that cannot be tested. Despite these theoretical and empirical impediments, portfolio analysis is a possible tool to help identify some compatible industries to be put on a targeted industries list, but it does not offer a complete solution to the development of a community's industrial recruitment strategy.

\section{REFERENCES}

Bahl, R. W., R. Firestine, and D. Phares. "Industrial Diversity in Urban Areas: Altemative Measures and Intermetropolitan Comparisons." Economic Geography 47 (1971): 414-425.

Cho, D. W., and A. C. Schuermann. "A Decision Model for Regional Industrial Recruitment and Development." Regional Science and Urban Economics 10 (1980): 259-273.

Conroy, M. E. "The Concept and Measurement of Regional Industrial Diversification." Southern Economic Journal 41 (1975): 492-505. "Alternative Strategies for Regional Industrial Diversification." Journal of Regional Science 14, no. 1 (1974): 31- 36.

Francis, J. C., and S. H. Archer. Portfolio Analysis. Englewood Cliffs, N.J.: Prentice-Hall, 1971.

Grossberg, A. J. "Metropolitan Industrial Mix and Cyclical Employment Stability." Regional Science Perspectives 12 (1982): 13-15.

Jackson, R. W. "An Evaluation of Alternative Measures of Regional Industrial Diversification." Regional Studies 18 (1984): 103- 112. 
Jensen, M. C. "The Performance of Mutual Funds in the Period 1945-65." Journal of Finance (1968): 389-416.

Kurre, J. A., and C. H. Woodruff. "Sensitivity of the Portfolio Variance Technique to Data Frequency and Type." Paper presented at the Twenty-Ninth Annual Meeting of the Southern Regional Science Association, Washington, D.C., 1990.

Lintner, J. "Security Prices, Risk, and Maximal Gains from Diversification." Journal of Finance 20, no. 4 (1965): 587-615.

Markowitz, H. "The Optimization of a Quadratic Function Subject to Linear Constraints." Naval Research Logistics Quarterly 3 (1956). . "Portfolio Selection." Journal of Finance (1952): 77-91.

Mossin, J. "Equilibrium in a Capital Asset Market." Econometrica 34 (1966): 768-783.

Richardson, H. W. Regional Economics. New York: Praeger Press, 1969.

St. Louis, L. V. "A Measure of Regional Diversification and Efficiency." Annals of Regional Science 14 (1980): 21-30.

Schoening, N. C., and L. E. Sweeney. "Applying an Industrial Diversification Decision Model to Small Regions." Review of Regional Studies 19, no. 3 (1989): 14-17.

Schrage, L. Linear, Integer, and Quadratic Programming with LINDO. Palo Alto, Calif.: Scientific Press, 1986.

Sharpe, W. F. "Capital Asset Prices: A Theory of Market Equilibrium Under Conditions of Risk." Journal of Finance 19, no. 3 (1964): 425-442. . "Mutual Fund Performance." Journal of Business (1966): 119-138.

Spahr, R. W., and R. F. Deckro. "A Non-linear Goal Programming Approach to Modeling Intraregional Economic Development." Review of Regional Studies 18, no. 1 (1988): 10-18.

Treynor, J. L. "How to Rate Management of Investment Funds." Harvard Business Review (1965): 63-74.

Wasylenko, M. J., and R. A. Erickson. "On Measuring Economic Diversification: Comment." Land Economics 54 (1978): 106-109.

Weston, J. F., and E. F. Brigham. Managerial Finance. New York: Holt, Rinehart, and Winston, 1972.

Wolfe, P. "The Simplex Method of Quadratic Programming." Econometrica (1959): 382-398.

U.S. Department of Commerce. County Business Patterns. 1966-1985. 